\title{
EXPLORING AFFORDANCES OF THE STREET
}

\author{
A. FURMAN \\ Faculty of Communication \& Design, Ryerson University, Canada.
}

\begin{abstract}
The streets and roads that form the majority of the circulation system in the urban network of the contemporary city have been undergoing some interesting changes that will be explored in this paper. Ever since signalized intersections and the idea of parking lots became a part of the city, many of the discussions regarding street use focused on the efficiencies of traffic circulation and parking vehicles. Recently, challenges to regulatory bodies by sharing companies such as Uber, MaaS, Airbnb and others, have brought to everyone's attention that the very idea of a parking spot, and even the need for car ownership is fast changing in the street and urban realm. This is only one of the many challenges to how public space is being rethought of by the sharing economy. Artists, activists and designers have been considering how the street has many affordances that can be employed to create new relationships of use through technology and by engaging the public to participate in the use and design of the street. Don Norman (1988) speaks of how an agent can interact with something, and this is seen as an affordance - Norman also asks us to look at the unintended accidental and anti-affordances things and spaces possess. What are the new relationships and opportunities to the shifting changes underway to the traditional public realm? Are actors/spectators playing an active role and no longer a passive one in the city streets? If streets are the arenas where the boundaries of conventional and aberrant behaviour are frequently redrawn' (Anderson 1978) then the potentialities of new affordances of the street will result in a reinvigorated public space.

Keywords: accidental affordance, active transportation, affordances, anti-affordance, bike lanes, circulation, network, public realm, public space design, roads, sharing economy, streets, technological adaptations.
\end{abstract}

\section{AFFORDANCES}

...a locus of personal exchange and communication

Rykwert, Joseph, The Street: The Use of its History [1]

Could this passage be interpreted as the tagline for a new advertising campaign promoting a social media application? That it comes from a historic survey of the changing nature of the dominant public space in all cities - the street, at a time when streets were not necessarily treated with the same regard as contemporary discourse on urbanity, demonstrates the ascendancy of social media as a parallel public sphere to the street. Social media aspires to the timeless definition of what makes a good street. When designing streets we strive to build streets that 'fit the needs and capabilities of people'[2]. Our definition of the street as a public space has qualities that essentially can be reduced to: it 'is physically comfortable and safe' [3]. The street can be understood as any poured surface, malleable and able to be shaped in 3D and creating a type of container or corridor capable of simply stopping abruptly, whereas a road implies a passage from one place to another, carrying people and cargo [4]. This then is the difference between a street and a road; the street has many diverse uses and permutations, culturally prescribed behaviours that are not required to afford pure function. When compared to discussions about 
the road and talk of roadways and road design, the conversation often implies a strong functional, instrumental approach to the design of the public realm, not concerned with the creation of new cultural meaning by the physical interaction (eye contact and close physical presence of human forms) along a surface that isn't mediated by a topological skin of steel and glass.

Since the area of street space does not change, for the most part, the property lines are the same, and buildings allow the public into the space affording some phenomenal (conceptual) transparency. In a way, this design problem is the raison d'etre of interior design planning strategy - to reformulate new relationships and programmes within the same interior (street). This type of thinking is useful for tactically modifying the street for the contemporary city.

Affordances can be described as all the possibilities in the world for how any agent (person, animal, or machine) interacts with something else [5]. Affordances are all the possible actions that may occur in a place, and the actions need to be discoverable by the user of the street in order to be properly enjoyed and used [6]. The cultural constraints of the street are slowly changing in North America, with great leaps having occurred with the push for asphalt promoted for road paving by the 1880 s cycling clubs, which led to improved sidewalks to make walking and moving on wheels more pleasant and efficient. The haphazard use of the early streets' affordance in the first decades of the last century gradually bifurcated and then grew with tarmac, referring less to pedestrian and cycling habits and more to encourage automotive and heavy transport vehicles to follow. Sidewalks became zones to control social behaviour with road design preoccupied with traffic flows and smooth banked entryways to freeways. Changing behaviour and the conventions of our times it seems, is incremental, Norman cautions us to reflect before adopting any novel ideas that disregard how powerful our existing cultural constraints are, which do not disappear quickly. Stanford Anderson looks at the street and conventions a bit differently; he suggests that societal change can happen without any large infrastructural changes, society can change 'without physical change,' it can take charge of the potential latency in the space [7], which seems to forecast changes in conventions, such as the current shifts occurring not with bricks-and-mortar but with social networks and mobility applications.

On the street confusion results with many differently abled vehicles all sharing the street lane, conventions exist but the majority stake of those that make up the bulk of actual traffic tend to define behaviour. Painted dashed line signifiers suggest universality of use for all but the reality is far from the original affordance of the street.

The accidental, the misunderstood, the unintended and unexpected are conditions that are, in some circumstances good for the ongoing project of the contemporary public realm, or street. Trying to engineer such a sequence of interpretation by the public in the street using the terms above would be a folly and probably would lead to heavily ironic and potentially unsafe spaces. When looking at the history of how circulation, specifically an internal street or corridor emerged in western society, Robin Evans pinpoints the date at about 1597 (From Figures, Doors, and Passages) to a British home that introduced the idea of separated rooms linked up by a corridor or hallway. The doors begin to have only one way in and out to the hallway. This is, according to Evans, a revolution in the way people and spaces have begun to be segregated [8], with an emphasis on a minimum of visual and physical contact being seen as desirable. If one compares this to the long history of adjacent rooms, with many different doors leading to other rooms, the differences in circulation and experience is quite apparent - and this shift in thinking about circulation systems of people and goods can be seen in the design of our current streets and public spaces, even our own homes. The publicness of the movement system reduces friction between parties. 
The 'interpretation of a perceived affordance is a cultural convention,' [9] Don Norman, an early advocate of the word Affordance, explores the relationship of the affordance of things to the design of things and space. James Gibson coined this word in 1979 [10]. Norman uses the doorknob as an example of a tool that has the perceived affordance [11] of grasp ability, and that, in certain cultures, it signifies that a portal can be opened or closed. If such a doorknob were to be placed on a wall, or on the floor, then the interpretation will be different. On the floor, it might be used to tie a dog's leash to, or it can be used to hang a coat onto if it were placed on a wall [12], and so on. The types of affordances in the design of streets that are intriguing are what Norman has coined accidental affordances, as the misplaced doorknob offers to cultures who use doorknobs, or if placed in a culture that does not use doorknobs for turning, which can become strongly suggestive (a signifier) to the public, especially if an affordance begins to be used for purposes that it was not originally intended for.

Today, we ask of our cities to come closer to the urban ideal of what a street/public space should be, and move away from the trend to 'segregate, contain, and enclose uses.' [13] Clear signifiers as to how to use the lane will help with safety and greatly increase the comfort of sharing the road when a separate bike lane takes away the many levels of confusion that exist between a cyclist and someone who is driving in the same lane. For example, the driver might be thinking: 'is this cyclist going to swerve into me because of the upcoming pothole?' or 'can I pass them quickly enough before the next intersection, and turn quickly?' Such thoughts races through both the driver's and cyclist's heads while both are engaged with sharing the same 9 feet width $(2.7 \mathrm{~m})$. Clearing up this century-long confusion of how to best use the street lane and curb in the city will lead to the reconsideration of other spaces along the city street as technology rapidly changes. The cultural constraints of the city have reinforced behaviours relating to the street including the sidewalk, the various types and functional affordances of street furniture, shop owner displays and the terms of engagement dealing with parking, curb cuts, and intersections. So we adapt and modify the space to be comfortable - the street pole affords leaning on, a tree becomes a good place to lock up a bicycle, overhangs and alcoves afford shelter, and a wider sidewalk becomes a place to sell your wares or busk to passersby. We can consider the unintended (accidental affordances) of things and spaces having to do with street design and use. Naturally, the winter city street has affordances that shift with the seasons; in winter the snow and ice tend to limit speed, types of activities (seating outdoors, cafe culture, etc.) and the warmer weather brings many more temporary events and uses. This recognition of the changing nature of the street, the public realm, underscores the importance of using the street in as many possible ways during the warmer months. One of the problems to overcome in urban street design is the legacy problem as coined by Newman [14]. It will involve jurisdictions and communities having to alter some of the physical conditions of the existing street to incorporate the need for width in sidewalk and cycling lanes (in street section) to lead towards an emancipation of the street.

\section{THE CHANGING PHYSICAL NATURE OF STREETS}

A street is a cultural surface that affords forward movement as well as a place to rest/to temporarily stop or park, and to communicate with the public. Circulation and the variegated options - the affordances available to the outdoor room that is the streetspace. When Gibson describes the ecological laws of materials, substances and surfaces he indicates that it is the surface of things 'where most of the action is.' [15] In the North American urban diet there tends to be more roads than streets in the use of our shared public ways. With roads/streets making up a third to a fifth of all public space in North American cities [16], the 
transformation of the street is not a small or isolated transformation of shared use. There is gathering momentum noticed with the public using terms that better define all users of space as being multi-mobile, complete streets, multi-modal, omnimobile users - being only some of the recently coined terms popular in use. A growing awarenes of the space hunger of the car is leading to reflection on the value the surface of asphal or sidewalk has when engaged in riding or parking of vehicles; there is a two-tier system that is being noticed. One wants to feel that they belong to the street and road. And when you think about it 'there's something that's quite empowering about parking your bicycle on the sidewalk,' [17] as compared to lifting your bike up onto the sidewalk and walking it to a vacant bike post. This strategy of inclusivity has been embraced with many cities implementing bike lanes between parked cars and the walking side of the street. Any form of empowerment that builds the levels of comfort and safety creates opportunities for other affordances on the street that were previously unthought of, especially if a street was felt to be alienating and dangerous. In an essay that Schumacher makes in the text On Streets, he presents an important diagram of a blended space between a cafe interior, an arcade, a walkway, and an extended cafe space shared by both the walkway and the public way observed in Italy. In this manner, Schumacher is diagramming a fuzzy space between uses and users that is made all the more dynamic by virtue of the pleasantness of the walking space and the diverse spectacle of people seeing each other walking, talking and eating inside and outdoors. [18] Such looseness of fit and comingling two activity zones is something to strive for in the slackening scenario of public parking and emerging sharing economy and what we can do with city street spaces.

The affordance of the street is a shared, human condition of varied and complex public and private experiences. It is important to state that it is being rewritten not only by the planning and municipal boards but by the emerging sharing economy, the mobility application applications and by the citizen organizations dedicated to sharing the street. Traditional views of street conventions (e.g. the only way to hire a temporary ride was to flag down a vehicle on the street or call a taxi dispatch service to hail a private vehicle for you) are being challenged by newer formats of mobility to connect and utilize the possibilities of the internet. In many instances, municipalities are playing catch-up with all the sharing apps that have shifted the terms of engagement between users through mobility devices and infrastructures. In 2002, Mark Wigley wrote prophetically that:

Interiority stops being that which is clearly defined by defensive walls and becomes a fragile effect of flows in circulation or traffic networks. The circulation network takes over, becoming more and more complex. It becomes the new interior (my italics). People occupy the circulation system rather than spaces connected by that system. [19]

Tridib Banerjee reminds us that in the North American context, there has not been much added physical public space (in terms of parks and open spaces) in recent decades. [20] He advocates that the planners do take an active role in bringing back needed rethinking about what constitutes the urban realm today and that the streets can be captured for social purposes, even though conventional land use planning treats streets as 'a simple circulation element of the general plan.' [21] Examples exists: consider the parkettes squeezed down to size--micro-PARK(ing) lot transformations that began way back in 2005 in San Francisco. These small plots of transformed roadway parking attest to the transformative power of incremental design named Everyday Urbanism by Margaret Crawford and others seeking a more community-based architectural response to street life. [22] Quentin Stevens would like to see 
more of the street life be incremental and open-ended, as well as flexible and reworkable. [23] He promotes using props that become architectural space-defining objects, play structures and street furniture. He also sees the value inherent in the idea of what accidental affordances found in places and things that do not reveal their meaning entirely. These elements are the 'microgeography of urban space' [24] In fact, we are talking about elements in street space that function to either connect or divide us; if we are comparing as to how the elements reinforce each other in the street it is useful to recall Simmels' preference of using the idea of a door to that of a bridge when imagining how to connect different zones, with the former simultaneously separating and connecting the thresholds of both interior and exterior realms. [25]

In the summer of 2016 there will be 135 on-street parking spots temporarily removed for the proposed demonstration bike lanes on Bloor Street West, the main eastwest artery across the city; it will have a $2.5 \mathrm{~km}$ dedicated bike lane along it. Changing the perception of the need for a better cyling design and how this will, in turn, improve other aspects of street and city life has been in the making for decades. [26] It takes a neighbourhood to raise awareness; five residents' associations, local councillors, business improvement associations, and cycling advocacy groups have worked with the city to propose this pilot study. [27] This important precedent, going forward, will be influential when decisions are made about the 10-year newly proposed city bike plan network.

Up until the 1960s there were plenty of free parking areas available in most large city centres. As soon as parking ceased to be free, driving and owning a vehicle began to lose some of its lustre as a symbol of independence and freedom. Some 50 years later, Toronto is taking a large step towards a new street paradigm, albeit slowly. Recognizing and enmeshing the different street presences along the bike lane experiment - the institutional university and civic buildings that stretch through the experimental route co-mingle with the neighbourhoods. Combining together such a diverse group with a bike reflects the fact that cycling itself is different than driving in the city, perhaps differing from the goals of other motorists. Cyclists represent a wide array of users: short-distance casual users of the street, sight-seeing, riding for pleasure, commuters, couriers, as well as dedicated athletes. Using both acquired muscle memory and recognition of the patterns of the street, along with the various seasonal and temporary events (i.e. rush hour or a sudden rainstorm) the new bike lanes and cyclists both serve and help to strive to create the resultant sympatric environment of commuting by making visible and adjusting street use itself.

\section{TRANSFORMATIONS AND GROWING TECHNOLOGIES}

Edward Tenner, in Our Own Devices writes that our lack of an 'unmediated contact' with the world that only the true hunter-gatherer enjoys is arguably a pressing problem that needs addressing. [28] Our growing separation from the natural surfaces and spaces might be better balanced with appropriately deployed technology on the city street; be it a bench, surface treatment of a bike lane, or a usable space for temporary street vendors and performers. Another way to look at the problem of the rising dissasociation we have with our physical spaces due to technologies is to harness technology back at the problem in order to create a richer street life. Raphael Lozano-Hemmer installed in various cities his relational architecture projection project and used the affordance of a large square or sidewalk and a backdrop of a wall or temporary scrim + scaffold to project onto a user-manipulated series of still images of people walking and using the street. Lozano-Hemmer has manufactured a temporary space of interaction (art) on the street in his Body Movies art project, where strangers 
stop by and pose to copy the silhouettes projected onto a wall, thereby setting off a computer sequence that advances to another image of different silhouettes. This temporary urban art work brings strangers together for a short while, improving the micro urbanity with technology. [29] Artists challenge cultural norms often as a strategy as part of their work. Don Norman suggests some examples of disrupting some everyday cultural norms: walking into an elevator and standing facing the back of the elevator, away from the others in the elevator, giving your seat up to the next athletic-looking person in a bus or streetcar. [30] These scripts governing our commonly understood local, cultural and social situations (e.g. how to behave in a restaurant, etc) sometimes have to be challenged in order to move beyond a banal streetscape that does not afford ('is for') much beyond walking.

The work of Acconci Studio mixes art practices with local, sensitive projects concerned with site-related concerns. The engaging street interventions in Memphis, Tennessee (2003), is a good example of how artists take advantage of accidental affordances and transform the use value of the unspecified and open-ended programme to great effect. The space (Fig. 1) is a typical corner urban condition, the sidewalk corner intersection adjacent to a modern building with some set-back to the street. The artist placed a permanent object that is both part of the sidewalk (it affords walking through it and beside it) and part of the private building (semi-public overhang space and property line). A free-form steel form defines two distinct interior 'rooms' for gathering and also provides some view 'cones' to appreciate the environment. This might be defined as street furniture or a shelter from the sun/rain, but it is not an example of large-scale public art that was prevalent in the decades after the 1960s. This form suggests alternate language and programme for the sidewalk that is adrift from city furniture standards and ordinances. The form transforms the public sidewalk into a sun shelter, walkthru space and outdoor performance/meeting rooms. Another unrealized project was to create a large-scale bicycle park in the Netherlands - it was to 'make the simple act of parking a bicycle an experience that is no longer banal and mechanical, but an eccentric act.' [31]

The emergence of applications such as Uber, MaaS, Airbnb, and so on, has disrupted the decades-long way of doing things. What was limited choice and many unknowns typical in travel and transportation is now being rewritten. The introduction of smart cars and vehicles to the street ecosystem in the near future will further challenge the ways streets are and will be configured. This will necessitate a new street paradigm, potentially revolutionary in scope, as the very notion of to park and ownership models associated with vehicles will be tested by

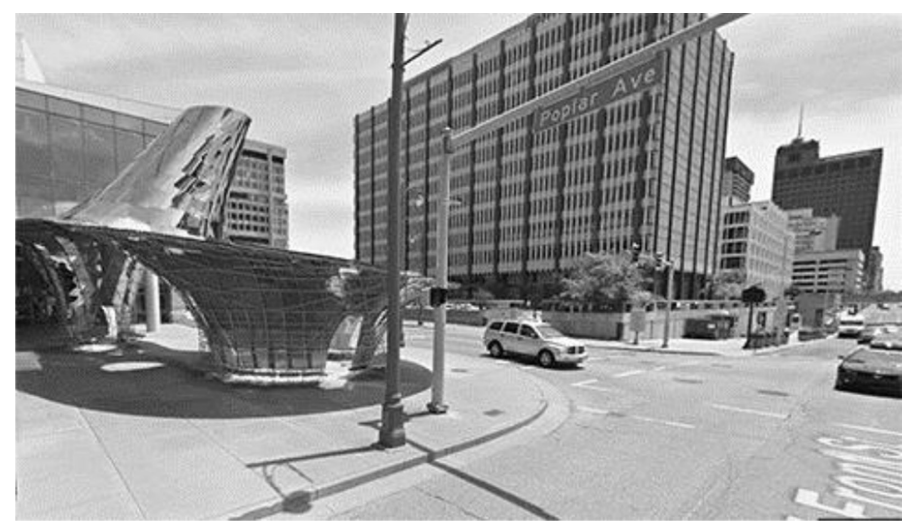

Figure 1: Google streetview, acconci studio street intervention in Memphis. 
the generations brought up with the linked, sharing economy to a future of mobility-connected networks. Mobility as a service (MaaS) coined by Sampo Hietanen, challenges traditional car ownership, and 'some transport sociologists say that information about mobility is $50 \%$ of mobility. The car will become an accessory to the smartphone.' [32] Thinking our way forward in this new virtual/real urbanity and streets in general, Martijn de Waal sees the individuals who self-assemble into like-minded groups as a model of minimal cohesion, rather than the worn public realm planning of the 1900s that attempted to bring everyone together, no matter their differences or diverse needs and wants for public space. de Waal sees this offspring of urbanity - the new public realm parallel to the physical publics, where protests and physical interactions may occur and that the interfaces of the city built form and the new media can both be modified and crowd-sourced effectively to build the types of community that we need to be sustainable in the city. Putting into practice this networked individualism [33] the public city can be incrementally adapted as part of this technological change that we are currently experiencing.

Our controlling hand upon the wrinkled ground is, as James Gibson puts it, making life easier for us, but has made life harder for most of the other animals. [34] We can paraphrase the ongoing transformations and creative connections for making the street (roadway) surface more convenient for quick auto travel: we have made the neighbourhood street life harder for everyone else. It also indicates that expediency has provided many opportunities for us to seek improvements to how we do things in the city. In the re-appraisal of the status quo, how we better understand the local dynamics of a place, as Georgeen Theodore states how important it is to 'understand the local dynamics' if you intend to affect the 'material flows and different systems of organization' in the urban network. [35] Incremental change happens, proceeded by a clear idea of how to disrupt established hierarchies of traditions that are in need of different thinking.

\section{CONCLUSION}

After a century, streets will return to people first. Don Norman reminds us that even though 'our technologies may change, (but) the fundamental principles of interaction are permanent,' [36] the street is much more than an instrument or a societally agreed upon well-made pathway, it affords the fullest human interaction in a public setting. It was always tied to the idea of mobility. Now mobility has moved beyond the street and road, and the state of the street's health and mobility in general is in an exciting time of change. It is not fully clear yet if we have reached peak car, but it seems that the rhetoric about any war on the car has somewhat dissolved, with cities around the world pledging to improve streets. The future of everyone's mobility seems to be headed towards further collaborative and sustainable models that propose different sustainable futures/options that imagine door-to-door service and/or multi-modal trips with all visions being less reliant on auto ownership. The solutions in the future are, it seems, in the hands of the design optimists and those who value the physical space interactivity of the street and their social networks.

\section{REFERENCES}

[1] Rykwert, J., The street: the use of its history. On Streets, ed. S. Anderson, The MIT Press: Cambridge, p. 23, 1978.

[2] Norman, A., Donald. The Design of Everyday Things, Basic Books: New York, p. 218, 2013.

[3] Jacobs, A.B., Great Streets, The MIT Press: Cambridge, p. 8, 1999. 
[4] Rykwert, Ibid, p. 16.

[5] Norman, Ibid, p. 18.

[6] Ibid, p. 145.

[7] Anderson, S., People in the physical environment: the urban ecology of streets. On Streets, ed. S. Anderson, The MIT Press: Cambridge, p. 7, 1978.

[8] Evans, R., Figures, doors, and passages. Space Reader: Heterogeneous Space in Architecture, eds. M. Hensel, C. Hight \& A. Menges, John Wiley \& Sons Ltd: Chichester, pp. 73-96, 2009.

[9] Norman, D., Affordance, Conventions, and Design, available at: http://www.jnd.org/ dn.mss/affordance_conv.html

[10] Gibson, J., The Ecological Approach to Visual Perception, Lawrence Erlbaum Associates Publishers: Hillsdale, 1986.

[11] Norman, A., Donald. The Design of Everyday Things, Basic Books: New York, p. 16, 2013.

[12] ibid.

[13] Loukaitou-Sideris, A. \& Ehrenfeucht, R., Sidewalks: Conflict and Negotiation Over Public Space, The MIT Press: Cambridge, p. 272, 2012.

[14] Norman, Ibid, p. 127.

[15] Gibson, ibid, p. 23.

[16] Nelson, A., When your parking grows up: What curb spaces can become, available at: http://grist.org/cities/when-your-parking-grows-up-what-curb-spaces-can-become/

[17] Nelson, ibid.

[18] Schumacher, P., Buildings and streets: notes on configuration and use. On Streets, ed. S. Anderson, The MIT Press: Cambridge, pp. 132-149, 1978.

[19] Wigley, M., Resisting the City. Transurbanism, eds. J. Brouwer, A. Mulder \& L. Martz, V2_Publishing/NAI Publishers: Rotterdam, pp. 103-122, 2002.

[20] Banerjee, T., The Future of Public Space: Beyond Invented Streets and Reinvented Places, available at: https://chisineu.files.wordpress.com/2013/03/the-future-of-publicspace.pdf

[21] Banerjee, ibid.

[22] Chase, J.L., Crawford, M. \& Kaliski, J. (eds.), Everyday Urbanism, The Monacelli Press: New York, 1999.

[23] Stevens, Q., The Ludic City: Exploring the Potential of Public Spaces, Routledge: New York, p. 197, 2007.

[24] Stevens, ibid, p. 210.

[25] Simmel, G., The Metropolis and Mental Life, 1903, available at: http://www.altruists.org/ static/files/the\%20metropolis\%20and\%20mental\%20life\%20(georg\%20simmel).htm

[26] Furman, A., Accommodating the Cyclist in the City, The Sustainable City IX, available at: http://www.witpress.com/Secure/elibrary/papers/SC14/SC14041FU1.pdf

[27] It's really a village, not a freeway, available at: http://gleanernews.ca/index. php/2015/07/31/its-really-a-village-not-a-freeway/\#.VypYn4Rlvsn

[28] Tenner, E., Our Own Devices: How Technology Remakes Humanity, Vintage Books: New York, p. 214, 2004.

[29] Lozano-Hemmer, R., Body Movies, available at: http://www.lozano-hemmer.com/ body_movies.php

[30] Norman, ibid, p. 129. 
[31] Aymonino, A. \& Mosco, V.P., Acconci studio: roof like a liquid flung over the plaza. Contemporary Public Space: Un-volumetric Architecture, Skira: Milano, pp. 196-197, 2006.

[32] Moss, S., End of the car age: how cities are outgrowing the automobile, available at: http://www.theguardian.com/cities/2015/apr/28/end-of-the-car-age-how-cities-outgrew-the-automobile

[33] de Waal, M., The City as Interface: How New Media Are Changing the City, NAI010 Publishers: Rotterdam, pp. 174-176, 2014.

[34] Gibson, ibid, p. 130.

[35] Yoos, R., A conversation with Juliette Spertus \& Georgeen Theodore. Beyond Patronage: Reconsidering Models of Practice, eds. M. Bohm, J. Hwang \& G. Printz, A Publication of the University of Buffalo School of Archiecture and Planning, Actar D: New York, pp. 87-94, 2015.

[36] Norman, ibid, p. 298. 